\title{
Echocardiographic and Computed-tomographic Evaluation of the Fate of Bovine Pericardial Patch as a Pericardial Substitute in Bentall's Procedure: Twenty-year' Results
}

\author{
Shikha Goja ${ }^{1}$, Lakshmi Kumari Sankhyan ${ }^{2}$, Ujjwal K. Chowdhury ${ }^{1 *}$, Niraj Nirmal Pandey ${ }^{1}$, Sudheer Arava ${ }^{1}$, Srikant Sharma ${ }^{1}$ \\ Abhinavsingh Chauhan ${ }^{1}$, Vishwas Malik ${ }^{1}$ \\ ${ }^{1}$ Cardiothoracic Centre, All India Institute of Medical Sciences, New Delhi, India. \\ ${ }^{2}$ Department of Cardiothoracic Surgery, All India Institute of Medical Sciences, Himachal Pradesh, India.
}

*Corresponding Author: Ujjwal Kumar Chowdhury, MCh, Diplomate NB ProfessorDepartment of Cardiothoracic and Vascular Surgery All India Institute of Medical Sciences Ansari Nagar, New Delhi-110029, INDIA.

Received Date: November 30, 2021; Accepted Date: December 30, 2021; Published Date: January 06, 2022

Citation: Shikha Goja, Lakshmi Kumari Sankhyan, Ujjwal K. Chowdhury, Niraj N. Pandey., Sudheer Arava., et all (2022). Echocardiographic and Computed-tomographic Evaluation of the Fate of Bovine Pericardial Patch as a Pericardial Substitute in Bentall's Procedure: Twenty-year' Results. $J$. Clinical Cardiology and Cardiovascular Interventions, 5(1); DOI:10.31579/2641-0419/234

Copyright: (c) 2022 Ujjwal Kumar Chowdhury, This is an open-access article distributed under the terms of the Creative Commons Attribution License, which permits unrestricted use, distribution, and reproduction in any medium, provided the original author and source are credited.

Abstract
Objective: The study was designed to ascertain the influence of usage of bovine pericardial patch in patients
undergoing Bentall's procedure with respect to reexploration for bleeding, mediastinal infection, avoidance of conduit
adhesions, late development of pericardial constriction and calcification.
Materials and Methods: We reviewed 150 patients ( 79 males) aged between 22 to 68 years (mean \pm SD $49.25 \pm 12.9$
years) receiving a composite aortic conduit between January 1998 to December 2020 for annuloaortic ectasia (n=100),
aortic dissection (n=49), and dilated aortic root in repaired tetralogy of Fallot (n=1). Twenty-five patients had Marfan's
syndrome. Modified "button technique" was performed by interposing a glutaraldehyde treated pericardial strip at the
graft coronary anastomoses, and proximal aortic conduit suturing using interlocking interrupted, pledgeted mattress
suture. On completion, the pericardial cavity was reconstructed using St. Jude Medical Biocor pericardial patch. To
detect evidence of pericardial constriction, survivors underwent echocardiography and computed tomography. The
Kaplan-Meier curve was drawn to show the probability of survival over a period of follow-up time.
Results: Seven (4.7\%) patients died of cardiac-related cause, $45 \%$ had transient hemodynamic instability, 55\% had
low cardiac output, and $87.1 \%$ had spontaneous return of sinus rhythm. The average 12 -hour postoperative drainage was
$245 \pm 70$ ml and there was no mediastinal infection. At a mean follow-up of 172.4 (SD \pm 58.9 ) months, the actuarial
survival was $94.2 \pm 0.04 \%$ ( $95 \%$ CI: $88.5-96.8$ ), and there was no pericardial constriction or calcification.
Conclusion: Reconstruction of pericardial cavity using Biocor bovine pericardial patch minimizes diffuse oozing of
blood, graft infection, and is not associated with later development of pericardial constriction, or calcification.
Key words: annuloaortic ectasia; aortic dissection; bentall's procedure; bovine pericardial patch; pericardial
calcification

\section{Introduction}

Since the introduction of glutaraldehyde by Alain Carpentier, bovine pericardium and other biological tissues have been used in clinical practice for the past 50 years. The biological tissues when subjected to low concentration of glutaraldehyde loses its antigenicity, does not induce the formation of antibodies, and produces the disruption of intra- and intermolecular protein, enhancing its structural stability, and maintaining sterility. [1-4]
The glutaraldehyde-treated bovine pericardium is one of the biological materials widely used in cardiovascular surgery as a patch material for aorta, pulmonary arteries, medium sized vessels, bioprosthesis valve leaflets, for repair of intracardiac defects, small vascular substitutes, and neoaortic reconstruction. The non-cardiac usage has been during tracheal reconstructive surgery, repair of diaphragmatic defects, and suture line reinforcement during lung volume reduction procedures, cholangioplasty, and inguinal hernia repair. [2,3,5-21] 
Literature documents isolated case reports on successful use of bovine pericardium in infected surgical field, namely, patch arterioplasty, and patch reconstruction of the mitral annulus following infective endocarditis.[22] However, larger case series as well as long-term results of use of this biomaterial in presence of infection is not available.[13,21,23-28]

The original Bentall's procedure employed an in situ circumferential suture line around the coronary ostia, then complete aortic wrap around to control bleeding. Tension developing at the suture line of the side-toside coronary anastomosis and/or blood accumulation within the perigraft space conveyed significant risk of coronary artery dehiscence, pseudoaneurysm formation and reoperation.[29,30] Hematoma in the space may additionally compress the graft or cause prosthetic valve dysfunction.[31-33]

To avoid this complication, Cabrol used a fistula to the right atrial appendage and subsequently adopted interposition Dacron conduits to the coronary ostia with the new risk of graft thrombosis and persistent aortoright atrial fistula. ${ }^{32}$ For these reasons, a modified open technique was developed by Kouchoukos and associates in 1986 that eliminated the prosthetic wrap and allowed reattachment of adequately mobilized coronary buttons to the graft with tension free sutures. [29]
Despite technical improvements in coronary arterial reconstruction by the "open button technique", graft-coronary anastomotic bleeding, bleeding from proximal and distal aortic conduit suture line, pseudoaneurysms of the coronary ostia anastomoses, pseudoaneurysms of the proximal and distal suture lines continue to occur because of fragility and reduced tissue quality of the ascending aortic wall and connective tissue abnormality. [20,31,34-41]

To address these concerns, we interposed a glutaraldehyde-treated autologous pericardial strip between the graft and native coronary ostia during coronary ostial implantation and placed interlocking, interrupted, pledgeted mattress sutures to ensure perfect hemostatic proximal aortic suture lines. The technical details and long-term results of coronary ostial and distal aortic anastomoses following modified Bentall's procedure have been addressed in our previous publications. [42-46]

Since the native pericardium was harvested for creating coronary buttons, bovine pericardium was used to cover the cardiac chambers and great vessels, including the conduit. From 1998 onwards, we reconstructed the pericardial cavity using a bovine pericardial patch to reduce/eliminate diffuse oozing from multiple needle holes and graft interstices, prevent the formation of postsurgical adhesions between the conduit and sternum, and as a protective material against graft inoculation (Figures 1A, 1B).
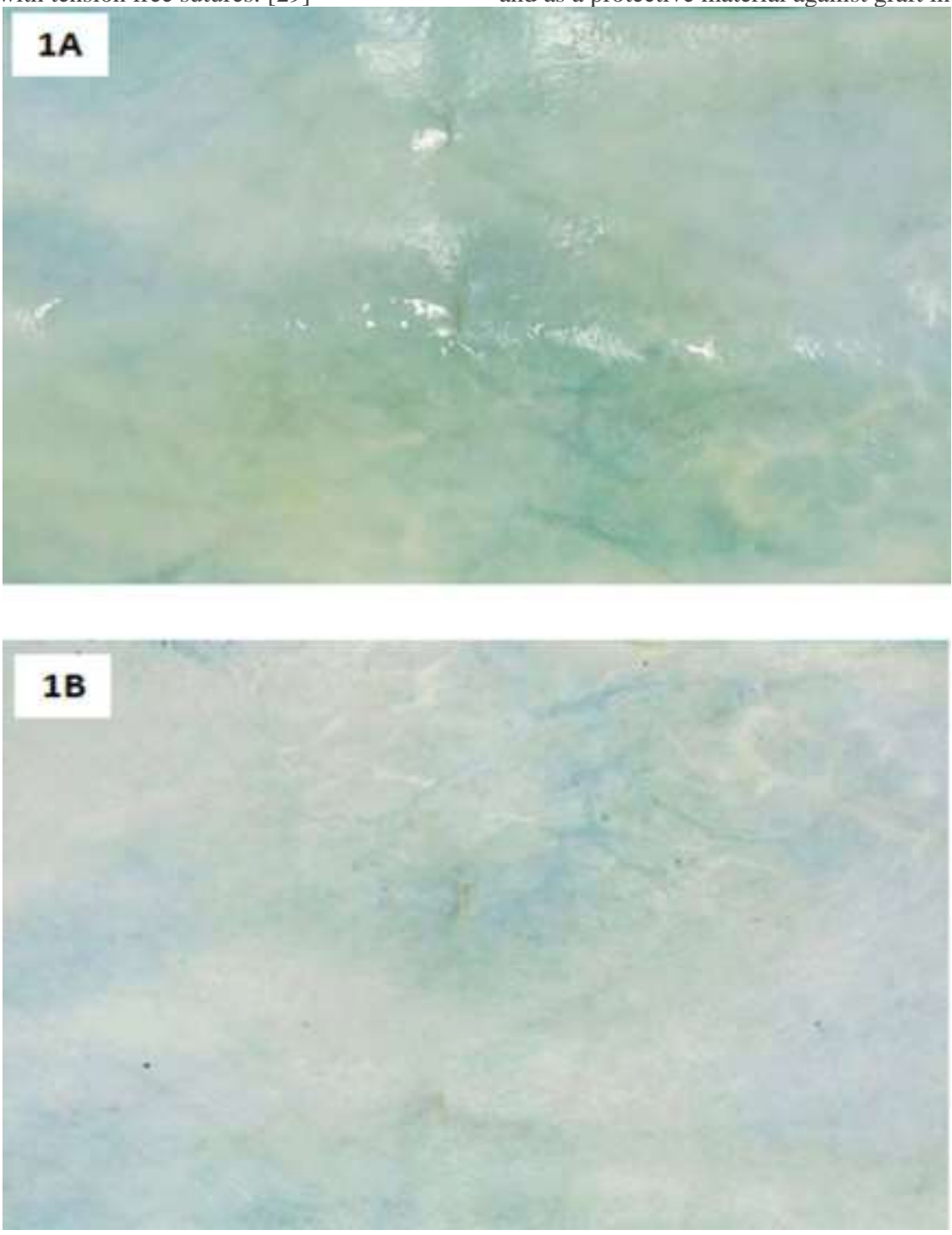

Figure 1A, 1B: Gross appearance of the Biocor (St. Jude Medical) bovine pericardial patch with rough surface (1A) and smooth surface (1B). 
Bovine pericardium is preferred because it's biocompatible, less antigenic, resistant to infection and acellular comprising essentially of pure collagen which may provide a natural microenvironment for host cell migration and proliferation, accelerating endothelization and tissue regeneration. [5-21]

Bovine pericardium is thoroughly washed and sutured with the rough surface facing intrapericardial side. Experimental data have demonstrated formation of covering layers with more plasticity, producing greater tension resistance and expansion when the rough face was placed intraluminally towards the vessel lumen, thus preventing aneurysmal dilation. [47]

The technical details of coronary button implantation, the long-term fate of coronary ostial and distal aortic anastomoses, and the myocardial preservation strategies of this group of patients have already been addressed in our previous publications. The same is not repeated here. [42-46] In this retrospective study, we present the very late-term (20 years) results evaluating: i) any reduction of diffuse bleeding and perioperative prosthetic graft infection, ii) the stability of newly reconstructed pericardial cavity over time, and iii) the fate of bovine pericardial patch in terms of thickening, constriction, and calcification assessed using echocardiography and computed tomography.

\section{Materials and Methods}

This study conforms to the principles outlined in the declaration of Helsinki of 1975, as revised in 2008. Between January 1998 to June 2021, 150 consecutive patients (79 males), aged 22-68 years (mean 49.25 \pm 12.9 years) underwent modified Bentall's operation using the surgical techniques described after obtaining informed consent and institutional ethics committee approval. This is the total number of Bentall's procedure done by the corresponding author in the last 23 years, and all patients are included in this study. Literature does not document any other studies citing the use of bovine pericardium as a pericardial substitute in patients undergoing Bentall's procedure. Therefore, the total number of operated patients in this study is totally based on subjective assessment by the corresponding author. Indication for surgery included annuloaortic ectasia $(n=100)$, type A aortic dissection $(n=49)$ and dilated aortic root following intracardiac repair of tetralogy of Fallot $(n=1)$. Moderate to severe aortic regurgitation was seen in $144(96 \%)$ patients, $6(4 \%)$ patients had grade II mitral regurgitation, and 105 (70\%) patients had left ventricular ejection fraction $<0.40$. Forty-three $(28.7 \%)$ patients underwent emergency operation while $8(5.3 \%)$ patients underwent concomitant coronary artery bypass grafting. [43,44] Patients' demographic details are shown in Table $\mathbf{1 .}$

\section{Echocardiography}

Transthoracic two-dimensional, color-flow Doppler echocardiography (Philips iE33 echo machine; Philips X7-2T probe, Bothell, WA, USA) was performed to measure mitral, tricuspid, superior vena cava, hepatic vein, pulmonary venous flow velocities, prosthetic valve motion, and transprosthetic gradients. Mitral or tricuspid regurgitation was assessed semiquantitatively as grade $1+$ to $4+$. Ejection fraction was calculated with a modification of the method of Quinones and colleagues. [48] A constrictive pattern was defined as pericardial thickening $>4 \mathrm{~mm}, 25 \%$ or greater increase in mitral E-velocity with respiration, and an augmented ( $25 \%$ or more) diastolic flow reversal in the hepatic vein after the onset of expiration compared with the inspiration phase.[49,50]

\section{Techniques of computed tomography}

Non contrast high pitch spiral acquisition was performed using a dual source computed tomography scanner (Somatom flash/ force, Siemens Healthcare, Forchheim, Germany). The scan was acquired in a craniocaudal direction, from above the level of carina upto the diaphragm.
Thin axial sections $(1.0 \mathrm{~mm}$, increment $0.6 \mathrm{~mm})$ were reconstructed using a medium-soft convolution kernel (B26). All reconstructed images were transferred to an external dedicated workstation (syngo.via, Siemens Healthcare, Forchheim, Germany) where multiplanar reformations, and volume rendered images were evaluated alongside axial images.

\section{Surgical techniques}

Intraoperative transesophageal echocardiography was performed with a Hewlett-Packard Sonos 1500 or 5500 ultrasound system on all patients. Standard anaesthetic and operative techniques were used throughout the study period. The operations were performed under moderately hypothermic cardiopulmonary bypass through arterial cannulation (axillary artery $n=28$; femoral artery $n=122$ ) and bicaval venous cannulation of femoral vein and superior caval vein.

A retrograde coronary sinus cannulation with self-inflatable balloon (RCO 14, Edwards Lifesciences, Irvine, CA, USA) was done using transatrial blind cannulation in 100 patients. In cases of difficult cannulation $(n=50)$, the coronary sinus was cannulated through a short right atriotomy under direct vision. Proper placement was confirmed by observing distension of posterior interventricular vein, maintenance of coronary sinus pressure, palpation of coronary sinus cannula posteriorly at the base of heart and transesophageal echocardiography.[51] No coronary sinus anomalies or coronary sinus injuries were confronted.

Ultrafiltration was used in all patients during and after cardiopulmonary bypass to reduce the total body water, potassium overload and to remove the inflammatory mediators from the circulation, maintaining hematocrit more than $25 \%$ on cardiopulmonary bypass.

All patients were subjected to the "integrated myocardial preservation management" strategy using intermittent antegrade direct ostial cardioplegia and retrograde coronary sinus cardioplegia infusion.[52] Cardioplegic infusions by both routes were never given simultaneously.

A dacron composite graft with a mechanical heart valve [(St. Jude Medical Inc.; Minn); (Conduit $25 \mathrm{~mm}(\mathrm{n}=60) ; 27 \mathrm{~mm}(\mathrm{n}=55) ; 29 \mathrm{~mm}$ $(n=35))$ was used in all patients. While creating the coronary buttons, the pericoronary diseased aortic tissue was excised leaving behind a cuff of $10-12 \mathrm{~mm}$.

All patients in the study underwent "modified button technique" for reconstruction of the coronary arteries and proximal conduit suturing for perfect hemostasis (Figures 2A-2I).

The technical details of the composite aortic graft replacement, the fate of the coronary ostial, and distal aortic anastomoses, and the myocardial preservation strategies have been enumerated in detail in our previous publications. ${ }^{42-46}$ The composite graft was sutured to the annulus using everted, interrupted 2-0 sutures over polytetrafluoro-ethylene pledgets. Each interrupted aortic supra-annular sutures were placed in such a fashion that successive sutures were made to pass through the previous pledget; thus ensuring perfect aortic annular hemostasis (Figures $\mathbf{2 A}$, 2B). Using graft cautery, two side holes were created on the composite graft measuring around $10 \mathrm{~mm}$ in diameter in the proposed area of coronary ostial implantation. The left and right coronary buttons were anastomosed in an end-to- side fashion with continuous 5-0 polypropylene suture to openings on the composite graft. While suturing, a long strip of glutaraldehyde treated pericardium, about $1 \mathrm{~cm}$ wide was interposed circumferentially around each graft-coronary button anastomosis (Figures 2C-2H). During construction of the inferior portion of the ostial anastomoses, the continuous retrograde perfusion was transiently lowered to avoid flooding and performing perfect hemostatic suturing under vision. 

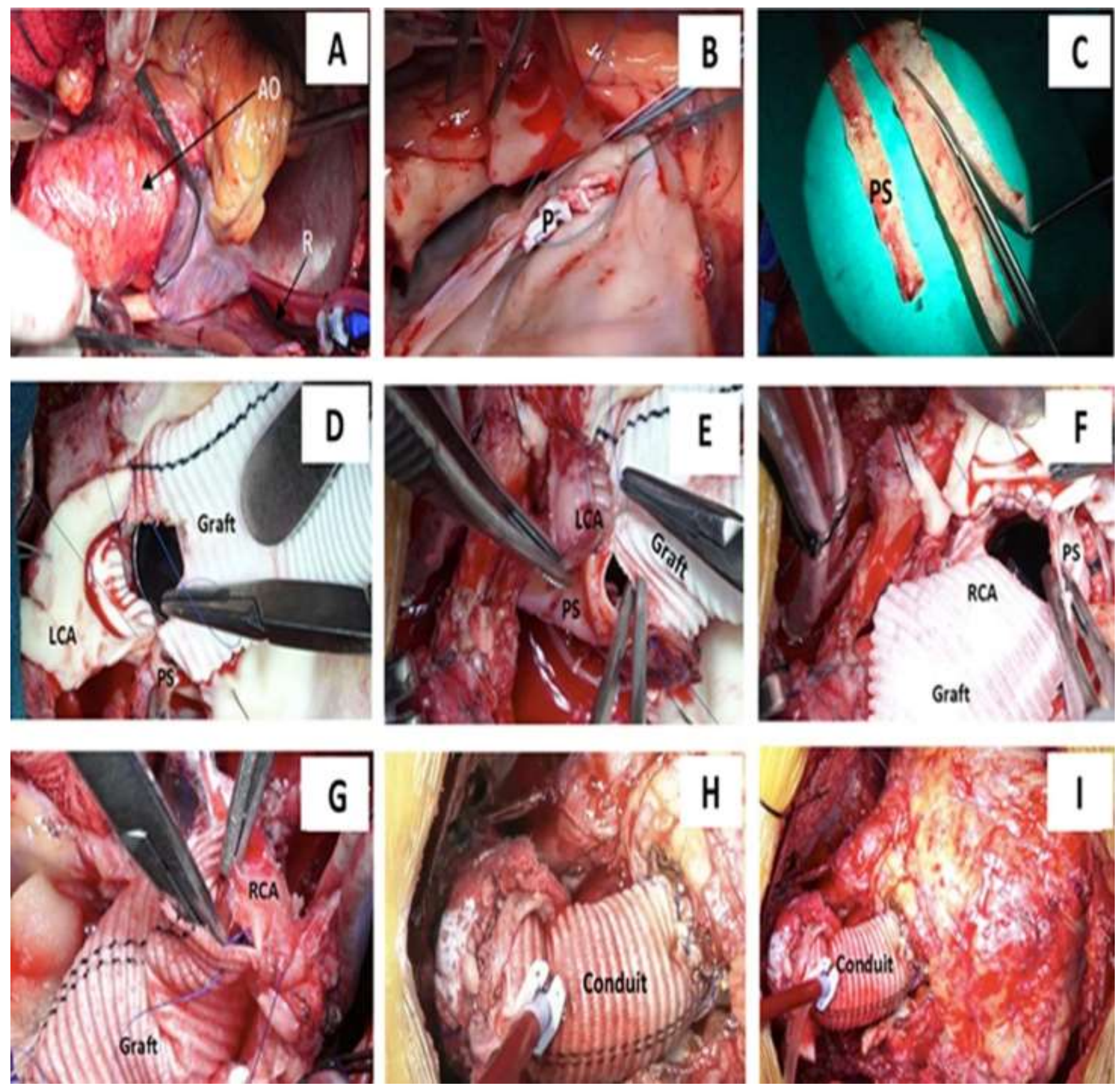

Figures 2A-2I: Surgical photograph of the techniques used for coronary button implantation and proximal aortic conduit suturing in the patient undergoing modified Bentall's procedure for annuloaortic ectasia.

Figures 2A, 2B: note placement of the coronary sinus cannula for continuous retrograde cardioplegia and the placement of interrupted pledgted mattress sutures for proximal aortic conduit suture line. Each interrupted suture is passed through the previous pledget interlocking with each other, ensuring perfect hemostasis.

Figure 2C-2H: step-by-step demonstration of graft-coronary anastomosis. Note the circumferential placement of the pericardial strip between the graft and the native coronary ostia.

Figure 2I : the completed placement of the composite aortic valved conduit [AO-Aorta; LA vent- Left atrial vent; LCA- Left coronary artery; PA vent- Pulmonary artery vent; P-Pledget; PS-Pericardial strip; R-Retrograde cardioplegia cannula; RCA-Right coronary artery]. 

$\min )$.

The right coronary button was anastomosed at a relatively high position of the composite graft taking into consideration the collapsed state of the right ventricle during cardioplegic arrest. We used topical thrombin (Tisseel, Baxter AG, Vienna) as an additional topical hemostatic agent on all patients.

Mean cross-clamp time was $114.6 \pm 28.4$ min (range, 90-187 minutes) and mean cardiopulmonary bypass time was $156.0 \pm 29.6$ min (range, 136-220

Following removal of aortic cross-clamp, majority of the patients $(\mathrm{n}=132$, $87.2 \%)$ returned to normal sinus rhythm. Only $18(12.8 \%)$ patients required antegrade administration of injection adenosine and $200-250 \mathrm{ml}$ warm hotshot blood cardioplegia for spontaneous defibrillation. Direct current cardioversion was not used on any patient. We used atrioventricular sequential pacing for 24-48 hours in patients with low heart rate.

On completion of the Bentall's procedure a segment $(15 \times 10 \mathrm{~cm})$ of bovine pericardium (SJM Biocor ${ }^{\mathrm{TM}}$ Pericardial Patch, St. Jude Medical,

\begin{tabular}{|c|c|}
\hline Variables & Number $(\%)$ \\
\hline Mean age at operation (range) & $\begin{array}{c}49.25 \pm 12.9 \text { years } \\
(22-68 \text { years })\end{array}$ \\
\hline Sex-Males & $79(52.7 \%)$ \\
\hline Annuloaortic ectasia & $100(66.7 \%)$ \\
\hline Type A aortic dissection & $49(32.7 \%)$ \\
\hline Repaired tetralogy of Fallot with aortic valvular reconstruction & $1(0.6 \%)$ \\
\hline Moderate-to-severe aortic regurgitation & $144(96 \%)$ \\
\hline Moderate mitral regurgitation & $6(4 \%)$ \\
\hline Left ventricular ejection fraction $<0.40$ & $105(70 \%)$ \\
\hline Marfans syndrome & $25(16.7 \%)$ \\
\hline Renal dysfunction & $75(50 \%)$ \\
\hline Concomitant coronary artery bypass grafting & $8(5.3 \%)$ \\
\hline $\begin{array}{l}\text { Operation timing } \\
-\quad \text { Emergency } \\
-\quad \text { Elective }\end{array}$ & $\begin{array}{c}43(28.7 \%) \\
107(71.3 \%)\end{array}$ \\
\hline Mean aortic cross-clamp time (range) & $\begin{array}{l}141.6 \pm 28.0 \text { minute } \\
(90-187 \text { minutes })\end{array}$ \\
\hline Mean cardiopulmonary bypass time (range) & $\begin{array}{l}156 \pm 29.6 \text { minutes } \\
\text { (136-220 minutes) }\end{array}$ \\
\hline In-hospital mortality & $7(4.7 \%)$ \\
\hline Late death & $3(2 \%)$ \\
\hline Mean hospital stay (range) & $\begin{array}{c}20 \pm 7 \text { days } \\
\text { (7-54 days, median } 10 \text { days) }\end{array}$ \\
\hline $\begin{array}{c}\text { Low cardiac output } \\
-\quad \text { Yes } \\
-\quad \text { No } \\
\end{array}$ & $\begin{array}{l}84(56 \%) \\
66(44 \%)\end{array}$ \\
\hline Average postoperative drainage ( 12 hours) & $250 \pm 56 \mathrm{ml}$ \\
\hline
\end{tabular}

Table 1: Demographic, operative, and postoperative details of the patients in the study $(n=150)$
Patients who needed moderate amount of inotropes (usually dopamine and/or dobutamine hydrochloride, $5 \mu \mathrm{g} / \mathrm{kg} / \mathrm{min}$ ) for less than 24 hours postoperatively were considered as having transient postbypass hemodynamic instability $(n=72)$. In contrast, patients who required inotropic agents, vasopressors and/or intra-aortic balloon counterpulsation for more than 24 hours postoperatively were categorized as having a true low cardiac output syndrome $(n=78)$.

Five patients required intraoartic balloon counterpulsation as an additional support of which three patients survived. The incidence of low cardiac output syndrome remained fairly constant over the course of the study.
St. Paul, MN, USA) was used to cover the cardiac chambers and great vessels including the valve conduit (Figures 1A, 1B).

\section{Statistical Analysis}

Statistical analysis was performed using Intercooled STATA 14.0 Software (College Station, Texas, USA). Interval related data were expressed as mean \pm standard deviation (SD) or median (minimummaximum) and categorical variables were expressed as percentages. The Kaplan-Meier curve was drawn to show the probability of survival over a period of follow-up time. The results were expressed as probability of survival (95\% confidence interval) at various time intervals. Statistical significance was set at $\mathrm{p}<0.05$.

\section{Results}

\section{Short-term outcomes}

There were $7(4.7 \%)$ early deaths due to low cardiac output syndrome with multiorgan failure and superimposed sepsis between $10^{\text {th }}$ to $18^{\text {th }}$ postoperative days. These patients had acute type A aortic dissection and were in congestive cardiac failure preoperatively (Table 1).

Variables

$(0.6 \%)$

$105(70 \%)$

$43(28.7 \%)$

$107(71.3 \%)$

$156+29.6$ minutes

-220 minutes)

$3(2 \%)$

$20 \pm 7$ days

$84(56 \%)$

$66(44 \%)$

\section{Morbidity}

Hospital morbidity included re-exploration for excessive bleeding from non-anastomotic sites within 12 hours in 8 patients with acute type A aortic dissection. The average 12-hour postoperative drainage was $245 \pm 70 \mathrm{ml}$. Twelve $(9.2 \%)$ patients required tracheostomy and long-term ventilator support. Hospital stay ranged from 7 to 54 days (median, 9 days; mean, $20 \pm 7$ days). Three patients were readmitted on $18^{\text {th }}, 21^{\text {st }}$ and $22^{\text {nd }}$ days postoperatively had deranged prothrombin time and required pericardiocentesis.

\section{Long-term outcomes}


There were $3(2 \%)$ late deaths at 15 and 69 months after surgery due to intractable ventricular arrhythmias and anticoagulant-related intracranial bleed respectively. Follow-up was $100 \%$ complete (1-226 months) and yielded 1218 patient-years of data. At a mean follow-up of 172.4 (SD \pm 58.9) months, the actuarial survival was $94.2 \pm 0.04 \%$ (95\% CI: 88.5-96.8). All survivors were in New York Heart Association I or II at their last follow-up. Two patients required thoraco-abdominal aortic graft replacement with re-implantation of celiac, superior mesenteric and right renal arteries 3 years following Bentall's procedure. No survivors had structural deteriorations, pseudoaneurysm formations or thromboembolic complications.

\section{Peri-operative myocardial infarction and arrhythmias}

No patients sustained a perioperative myocardial infarction. Postoperatively, 16 (10.7\%) patients had supraventricular arrhythmias, 8 (5.4\%) had premature ventricular contraction, $2(1.3 \%)$ had ventricular tachycardia, $14(9.3 \%)$ had left bundle branch block, and $10(6.7 \%)$ had junctional rhythm. No patient had complete heart block.

\section{Postoperative studies and results}

All survivors $(\mathrm{n}=140)$ were examined and studied between December 2019 and June 2021, which was the closing interval of the study. Postoperative evaluation consisted of clinical examination, electrocardiogram, chest radiograph, cine fluoroscopy, echocardiography and computed-tomographic angiography. The functional class at followup was noted. All patients received warfarin and aspirin (100 mg/day) for anticoagulation to maintain INR between 2.5 to 3.5. Digoxin and diuretics were weaned at varying time intervals. Amiodarone was used for intractable atrial fibrillation.

Postoperatively, the left ventricular ejection fraction increased from $50 \% \pm 9.2 \%$ (range $15 \%$ to $62 \%$ ) to $58 \% \pm 6.2 \%$ (range $15 \%-70 \%$ ). Thirtynine $(26 \%)$ patients had left ventricular ejection fraction ranging between $15 \%$ and $25 \%$.

At a mean follow-up of $172.4 \pm 58.9$ months, none of the survivors demonstrated anastomotic complications involving the coronary ostia or the distal aortic arch. All patients demonstrated patent coronary ostia and with no coronary aneurysm, kinking or pseudoaneurysm formation of the newly implanted coronary arteries (Figure 3). None of the survivors had either constrictive pericarditis or pericardial calcification.

\section{Cohort of survivors}

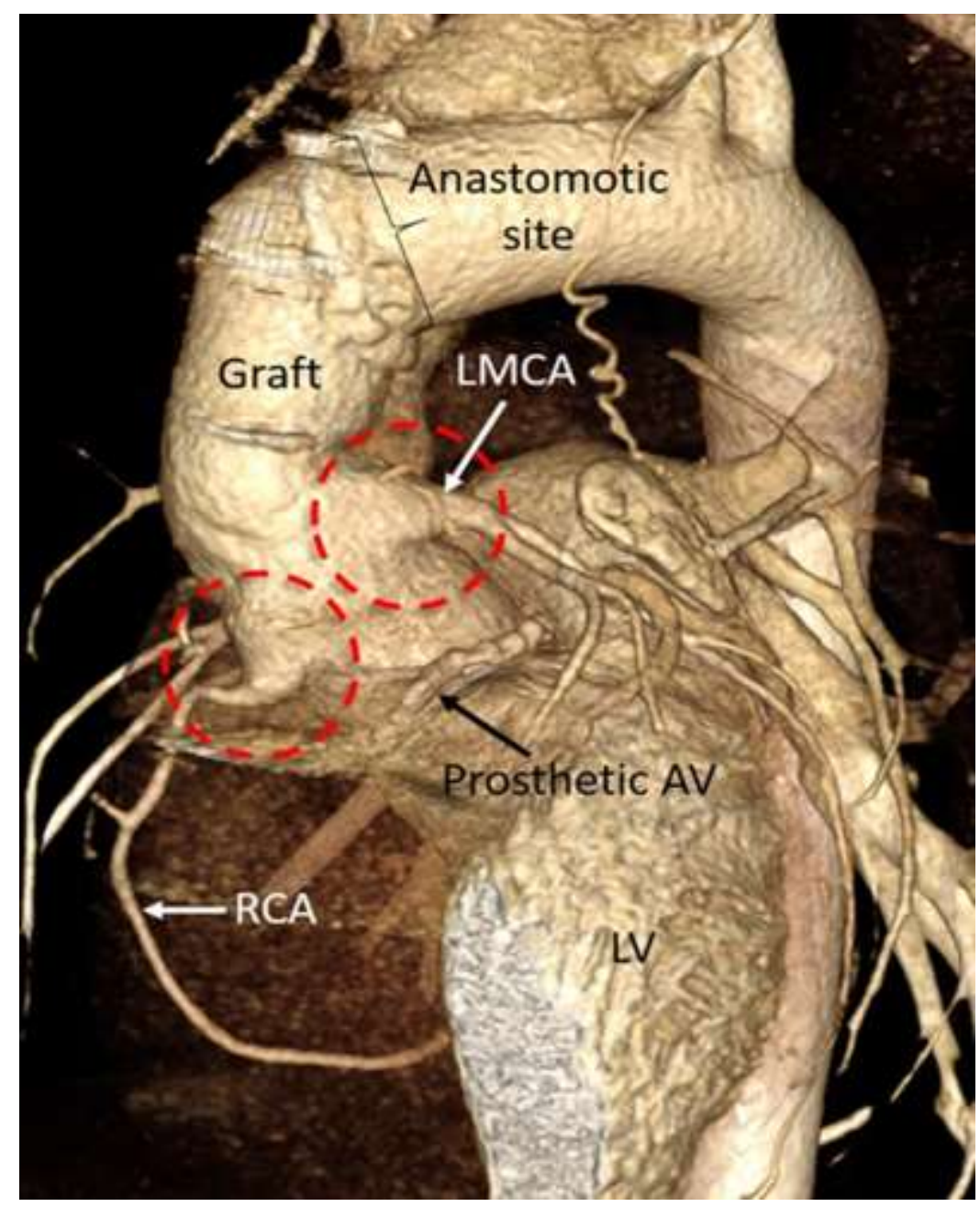

Figure 3: Computerized volume rendered image at 15th postoperative year in the left anterior oblique projection with cranial tilt in this study revealed widely patent left and right coronary arterial systems, intact proximal and distal anastomoses. There are no coronary ostial kinking / narrowing / aneurysm or pseudoaneurysm formation of the coronary arterial system

[Prosthetic AV-Prosthetic aortic valve; DTA-Descending thoracic aorta; LAD-Left anterior descending coronary artery; LCX-Left circumflex artery; LMCA-Left main coronary artery; $L V$ - Left ventricle] 


\section{Discussion}

The present study is the first to our knowledge to determine the very lateterm (20 years) results of bovine pericardium as a pericardial substitute in the setting of Bentall's operation. The study provided several interesting findings: i) no patient exhibited clinical or echocardiographic features of constrictive pericarditis, ii) computed-tomography did not reveal any instances of pericardial thickening or calcification and iii) the average postoperative drainage volume was $249 \pm 65 \mathrm{ml}$ in the first 12 hours following surgery, with no instance of graft/mediastinal infection on any patient.

The quest to establish a pericardial substitute that is durable for 20-25 years without causing any pericardial adhesions, and adverse hemodynamics continues. Various biologic or synthetic sheets such as absorbable polymer patches, three-layered synthetic pericardial substitutes, and expanded polytetrafluoroethylene have been used as a pericardial substitute.[52-54] However, there have been no documented adequate substitutes that reduces postsurgical adhesions.[53] Prevention of adhesions through pericardial substitution has therefore become a matter of investigation.[55]

Bovine pericardium has come into common clinical use during the past 50 years, especially when used as a patch for arterial closure during vascular and cardiac surgery. Technical merits that have led to widespread adoption of bovine pericardial patches in the operating room, include easy handling, less suture bleeding and the ability to immediately perform arterial duplex examination at the site of angioplasty.[5-21] However, long-term results of this biomaterial are poorly documented and need cautious interpretation as to whether its long-term performance is related to the material itself or to the operation in which it is used.[1,13,14]

\section{Experimental basis and clinical applications of bovine pericardium as a biomaterial}

The advantages of bovine pericardium as a cardiovascular patch can be divided into clearly observed and documented advantages, and benefits that are not well documented so far. The clearly documented advantages are: i) biocompatibility; ii) minimized antigenicity, increased strength and stability due to pretreatment using glutaraldehyde; iii) dependable suture retention due to consistent processing with $0.5 \mathrm{~mm}$ thickness pericardium; iv) reduced potential infections; v) increased long-term durability; vi) similarity of compliance of bovine pericardium and native artery/prosthetic conduit; and vii) feasibility of insonation with ultrasound immediately after implantation due to lack of air spaces and solidity.[3,21,25,26,57-59]

Although being used in clinical practice, there are instances where benefits of bovine pericardium not as well documented, for example: i) use of bovine pericardium as a vascular patch of medium sized arteries namely, carotid, femoral, and popliteal arteries following embolectomy or endarterectomy, ii) closure of intracardiac defects like atrial and ventricular septal defects, $[5,7,17]$ iii) repair of arteriotomy in the presence of infected field despite lack of evidence of it being bacteriostatic or bactericidal, ${ }^{11,12}$ and iv) claim of some manufacturers that bovine pericardium possess anticalcification technology that can significantly reduce calcification, and support endothelization. [8,9,27,6-65]
Bovine pericardium being an acellular material of essentially pure collagen, may provide a natural microenvironment for host cell migration, and proliferation, accelerating endothelization, and tissue regeneration.[66,67] Since primary closure of a longitudinal arteriotomy may result in restenosis due to neointimal hyperplasia, patch arterioplasty is advocated to prevent this complication. Most commonly, patch angioplasty is performed after carotid endarterectomy and in femoral and popliteal arteries following thrombectomy or embolectomy. Metaanalysis provides strong evidence that carotid patching provides both perioperative and long-term benefits after carotid endarterectomy.[8,9,11,27,61-63,65,68-74]

Published literature is divided on the selection of patch material for carotid endarterectomy. Vein patch angioplasty ideally should have the lowest incidence of postoperative thrombosis due to an intact endothelium, an inherent suppleness and natural compliance. Several investigators have reported equally encouraging results using bovine pericardial patch and synthetic patches.[61,69-72]

Although there are morphological similarities, the molecular and cellular pathways that stimulate intimal hyperplasia in these clinical circumstances may be different. The biological signaling pathways that activate vascular healing after patch angioplasty depend on cells that infiltrate the patch and different patches may have different biological responses and therefore may need different types of treatment.[8,9,11,27,61-63,65,68-74]

Although scientific evidence of bovine pericardium as bacteriostatic and bacteriocidal is scanty, it has been used to repair arteriotomy in the presence of infected field.[11-14,21,25-27,74,75] Prosthetic patch infection after carotid endarterectomy has been estimated to be around $0.4 \% .{ }^{26,75}$ Investigators have demonstrated similar risk of postoperative infection comparing bovine pericardium, autologous vein patches, and synthetic patches.[6,11,12,74,75] However, until an underlying mechanism of resistance to infection e.g. contact cytotoxicity is demonstrated, one cannot convincingly state that bovine pericardium is immune from becoming infected. The fundamental strength of glutaraldehyde fixed bovine pericardial patch may be responsible for low rate of degeneration and resistance to infection.

Fibrosis of patches is unusual and reports of bovine pericardium patch fibrosis are distinctly rare.[77,78]. It is likely that the mechanisms that induce patch calcification may be similar to those that induce patch fibrosis, although with subtle differences. Further research may help identify fibrocyte-specific signaling pathways as potential therapeutic targets to prevent bovine pericardium fibrosis.[79]

Since the primary problem of xenografts is structural deterioration at long-term, mainly due to calcification, several improvments in the processing of xenografts and placement of the pericardial patches have been implemented to prevent structural deterioration and dystrophic calcification.[8,9,46,80-83]

The native structure of bovine pericardium has three layers: i) the thin inner serosal layer consisting of mesothelial cells; ii) the thicker fibrosal layer formed by diversely oriented, wavy bundles of collagen and elastin; and iii) the outer epipericardial connective tissue layer that is partly continuous with the pericardiosternal ligaments (Figure 4A-4D). 

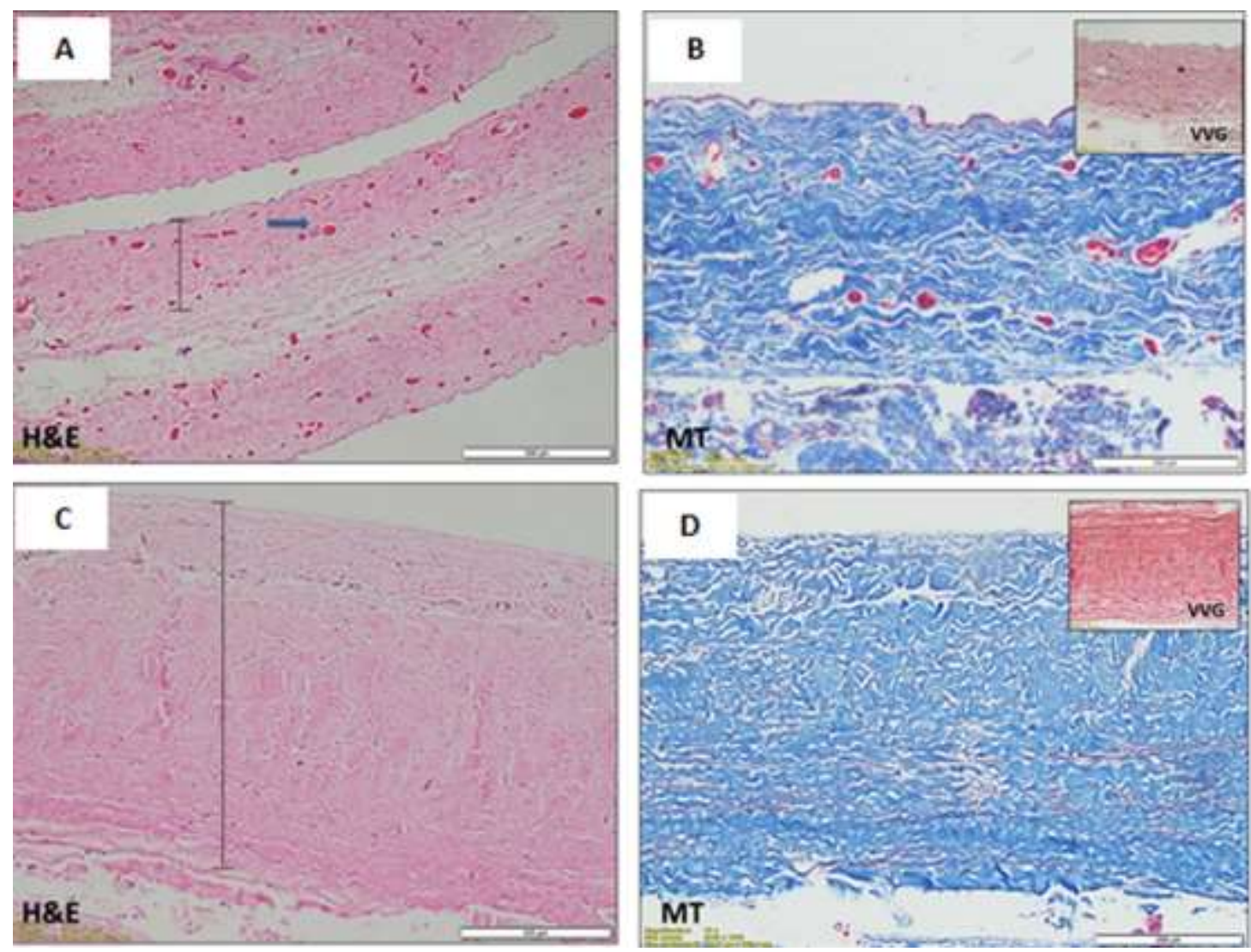

Figures 4A-4D: Microscopic examination of pericardium: From the human (A and B) shows outer mesothelial lining, inner thin fibrous layer with presence of congested blood vessels (Arrow). Special stain (MT and VVG [inset]) highlighting the collagen with minimal elastic tissue within it. From the bovine pericardium (C and D) shows only thick fibrous layer with lack of elastic tissue within it. Special stain highlighting the pericardial collagen (MT and VVG [inset]).

$H \&$ E: Hematoxylin and eosin stain, MT: Masson trichrome stain (collagen:-Blue colour), VVG: Verhoeff van Gieson stain (Elastic tissue :-Black colour)

Commercially available patches are processed to be acellular, preventing transplantation of bovine proteins or DNA into the host. Gluteraldehyde is a typical processing agent, crosslinking - $\mathrm{NH} 2$ groups of lysine, hydroxylysine, or the $\mathrm{N}$-terminus of amino acids, to form amine linkages with the elimination of water; these amine linkages form covalent bonds between adjacent proteins that are stable at physiological temperature and $\mathrm{pH}$. The resultant cross-linkage of xenograft tissue with glutaraldehyde increases tissue strength to inhibit biodegradation, stabilizes collagen, and reduces antigenicity.[1,57,66,67,80-92]

However, glutaraldehyde fixation promotes dystrophic calcification because of the chemical process between free aldehyde groups, phospholipids, and residual antigenicity of the bioprosthetic tissue.[1,8085] Series of experimentation over several years through basic research have been directed toward developing a tissue treatment process to prevent calcification in glutaraldehyde fixed xenograft tissue. The aim of the anticalcification strategies is to extract lipid or to neutralize toxic residual aldehyde.[92-95]

Residual free aldehyde groups or polymerized forms of glutaraldehyde create a locally cytotoxic environment and result in tissue calcification. Amino acid post fixation improves protein cross-linking to increase the mechanical performance of bioprostheses or to neutralize these free aldehyde groups because the amino groups of these compounds can react with the free aldehyde groups of glutaraldehyde, forming Schiff base.[86,87,94,95] In 2009, Zhou et al demonstrated utiliy of sodium bisulfite, a classic reductive agent which reacts with aldehyde to form $\square$ - hydroxyl sodium sulfonate, and would react with any free glutaraldehyde in fixed pericardial tissue, thus minimizing in vivo calcification.[96]

Short-chain alcohols, such as octanol at high concentration $(>50 \%$ in aquous buffers) reduce calcification potential of aldehyde-fixed tissues by removing phospholipids or conformational changes in collagen.[87,92,93] The alcohols may also be preferentially bound to hydrophobic residues within collagen and elastin which may undergo independent calcification. [88,97]

Long-chain alcohols such as oetanol 1, 2-octanediol along with shortchains, and isopropanalol have been used along with a buffered ethanol solution to remove phospholipids more efficiently.[90,92,93,98]

The key common feature for the pathophysiology of calcification is involvement of devitalized cells and cellular debris.[80-83] There is a debate in the literature as to whether there is an immune response to bioprosthetic tissue.[80-83] Recently, it has been found that the mammal cell surface xenoantigen called $\square$-Gal epitopes are still present on the commercially available glutaraldehyde fixed tissues.[84] Patients undergoing bioprosthetic valve implantation have exhibited a significant rise in anti- $\square-$ Gal antibodies.[99-104] Decellularization suppresses the rise anti- $\square$-Gal antibodies titre. However, the pathogenesis of dystrophic pericardial calcification remains conjectural.

Other investigators have introduced genipin, derived from the fruits of Gardenia Jasminoides as a novel cross-linking agent because this naturally occurring cross-linker is less cytotoxic and better in vivo 
biocompatible than glutaraldehyde.[66,67,89] Park and associates have used recombinant human alpha galactosidase A to remove alpha-gal epitopes from porcine aortic valve.[105-107]

Despite good results of bovine pericardium in several clinical trials, degeneration of biological tissue including calcification is frequently observed.[80-83] Piers and colleagues suggested a possible correlation between calcification and contact of the rough face of the pericardium with the blood stream.[8,9] In 2011, Saporito and colleagues demonstrated experimentally that the bovine pericardium preserved in glutaraldehyde did not show alterations in its structure when implanted with different faces turned to the inner portion of vessels.[46] There was aneurysmal dilation of the implant site when the smooth face was turned to the intraluminal side. When the rough face was turned intraluminally, there was formation of a covering layer with more plasticity, modeling elastic tendon and bone formation which produced greater tension resistance, preventing its expansion. Piers and colleagues demonstrated the formation of internal apposition fibrosis on the surface of the retail. The wrinkled surface of the retail facilitates capture and adhesion of blood components and subsequent assemblage by the release of platelet factors and secondary released thromboplastin. $[8,9,108]$ In this study, all patients underwent reconstruction of the pericardial cavity using bovine pericardium with the rough surface facing the cardiac chambers, and great vessels.

Some investigators have reported that if smooth muscle cells and/or fibroblasts migrate into the bovine pericardium patch, the patch may provide an environment that promotes subsequent calcification and degradation.[94,95] Hruska and associates summarized the currently accepted major theories regarding the mechanism and regulation of vascular calcification: i) abnormal calcium and phosphate homeostasis, ii) failure of anticalcific mediators, iii) induction of osteochondrogenesis, iv) apoptosis, v) circulating nucleatic complexes/paracrine factors derived from bone, and vi) matrix degradation.[109-113]

As these etiologies become more understood, it is possible that preventive strategies may be able to be incorporated into future generations of patches, i.e. incorporation of anticalcific mediators, remesothelialization on the surfaces of the implanted patch. [97,98,101-104,109-113,119,120] These next generation patches might be particularly useful for patients with chronic kidney disease, type 2 diabetes mellitus, and elderly, who might be at increased risk of patch calcification and degradation.[114]

When bovine pericardium is used as a vascular patch, the collagen surface of the bovine pericardial patch may be a nidus of thrombus formation. However, thrombosis of bovine pericardium patches has not been reported to be a major problem, either acutely or chronically. In clinical practice, most institutions routinely administer Dextran-40 for 24 hours post endarterectomy to prevent thrombus formation and propogation at the site of thromboendarterectomy.

\section{Exploring the unknown: Future Directions}

This communication is not meant in any way to convince those surgeons satisfied with their own methods of performing a Bentall's procedure. Rather it hopes to pointout that reconstructed pericardial cavity is beneficial preventing inoculation with infected mediastinal wound, minimizes diffuse oozing, and avoids postsurgical periconduit adhesions.

Can intimal hyperplasia be avoided by seeding mesenchymal stromal cells on bovine pericardium? Investigators have used bovine pericardium as the scaffold for the seeded multilayered mesenchymal stromal cells to provide a base for uniform cardiac tissue regeneration. ${ }^{115}$ They have demonstrated that this novel bioengineered tissue graft can serve as a useful cardiac patch to restore the dilated ventricle and stabilize cardiac functions after myocardial infarction. ${ }^{115}$ Interestingly, the authors reported increased density of neomicrovessels in the tissue engineered patches compared to control patches, suggesting that tissue regeneration occurs within the porous bovine pericardium through a process involving cell recruitment and tissue-specific differentiation.

Investigators have demonstrated that acellular bovine pericardial tissues fixed with genipin could provide a natural microenvironment for host cell migration, and may be used as a tissue engineering extracellular matrix to accelerate tissue regeneration. ${ }^{115} \mathrm{In}$ an attempt to reduce postsurgical pericardial adhesions, researchers are experimenting on mesothelial regeneration on acellular bovine pericardia loaded with an angiogenic agent (ginsenoside Rg1).[66,67,105-107,115-120] This exciting research shows the prospect for delivering cell therapy, in a site-specific manner, with bovine pericardial patches.

\section{Conclusions}

Reconstruction of the pericardial cavity using bovine pericardial patch minimizes diffuse oozing of blood, mediastinal infection, and is not associated with late development of pericardial constriction and calcification. Understanding the mechanisms by which bovine pericardium heals after patch angioplasty may lead to next generation tissue engineered patches. Process of decellularization, use of alcohol, newer preservatives like genipin and mechanism of healing of bovine pericardial patches may improve the long-term durability of bovine pericardial patch.

\section{References}

1. Carpentier A, Lemaigre G, Robert L, et al. Biological factors affecting long-term results of valvular heterografts. J Thorac Cardiovasc Surg 1969; 58(4): 467.

2. Ionescu MI, Smith DR, Sutherland TW, Wooler GH. Heart valve replacement with aortic heterografts: Follow-up study. Ann Thorac Surg 1972; 13(1): 1-4.

3. Ionescu MI, Tandon AP, Mary DA, Abid A. Heart valve replacemt with Ionescu - Shiley pericardial xenograft. J Thorac Cardiovasc Surg 1977; 73(1): 31-35.

4. Braile DM, Bilaqui A, Ardito RV. Prótese de pericárdio bovino- 44 meses em 164 pacientes. Anais do nono congresso nacional de cirurgia cardiac 1981; 4-5: 44.

5. Us MH, Sungun M, Pocan S, et al. A retrospective comparison of bovine pericardium and polytetrafluoroethylene patch for closure of ventricular septal defects. J Int Med Res. 2004; 32(2): 218-221.

6. Provencher S, Deslauriers J. Late complication of bovine pericardium patches used for lung volume reduction surgery. Eur J Cardiothorac Surg. 2003; 23(6): 1059-1061.

7. Wang Y, Xu YD, Li JS. Cholangioplasty by using a patch of bovine pericardium in treatment of stricture of extrahepatic bile duct. Zhonghua Wai Ke Za Zhi. 1994; 32(5): 269-270.

8. Pires AC, Saporito WF, Leão LEV, et al. Bovine pericardium as a vascular patch. Rev Bras Cir Cardiovasc 1997; 4(3): 190194.

9. Pires A, Saporito WF, Leão LEV, et al. Bovine Pericardium used as a Cardiovascular Patch. The Heart Surgery Forum 1999; 2(1): 16830-168304.

10. Alpagut U, Ugurlucan M, Kafali E, et al. Endoluminal stenting of mycoticsaccular aneurysm at the aortic arch. Tex Heart Inst J 2006; 33: 371-375.

11. David TE. The surgical treatment of patients with prosthetic valve endocarditis. Semin Thorac Cardiovasc Surg. 1995; 7 : 47-53.

12. Jones JM, Sarsam MA. Partial mitral valve replacement for acute endocarditis. Ann Thorac Surg. 2001; 72: 255-257.

13. McMillan WD, Leville CD, Hile CN. Bovine pericardial patch repair in infected fields. J Vasc Surg 2012; 55: 1712-1715. 
14. Li X, Guo Y, Ziegler KR, et al. Current usage and future directions for the bovine pericardial patch. Ann Vasc Surg 2011; 25: 561-568.

15. Fraser III CD, Arnaoutakis GJ, George TJ, et al. Acute cholecystitis preceding mycotic aortic pseudoaneurysm in a heart transplant recipient. J Cardiovasc Surg 2010; 25: 749-751.

16. Vaughn CC, Vaughn PL, Vaughn CC, et al. Tissue response to biomaterials used for staple-line reinforcement in lung resection A comparison between expanded polytetrafluoroethylene and bovine pericardium. European Journal of Cardio-thoracic Surgery 1998; 13: 259-265

17. Barbetakis N, Samanidis G, Paliouras D, et al. Intraoperative tracheal reconstruction with bovine pericardial patch following iatrogenic rupture. Patient Saf Surg. 2008; 2: 4.

18. Limpert JN, Desai AR, Kumpf AL, et al. Repair of abdominal wall defects with bovine pericardium. Am J Surg 2009, 198(5): e60-365.

19. Wang Y, Xu YD, Li JS. Cholangioplasty by using a patch of bovine pericardium in treatment of stricture of extrahepatic bile duct. Zhonghua Wai Ke Za Zhi. 1994; 32(5): 269-270.

20. Szerafin T, Leny A, Palotas L, et al. Abdominal hernia repair with no-react treated bovine pericardial patch. Magy Seb. 2008; 61 Suppl: 61-65.

21. Zientara A, Schwegler I, Dzemali O, et al. Xenopericardial selfmade tube grafts in infectious vascular reconstructions: preliminary results of an easy and ready to use surgical approach. Vascular 2016; 24(6): 621-627.

22. David TE. The use of pericardium in acquired heart disease: a review article. J Heart Valve Dis 1998; 7: 13-18.

23. Czerny M, von Allmen R, Opfermann P, et al. Self-made pericardial tube graft: a new surgical concept for treatment of graft infections after thoracic and abdominal aortic procedures. Ann Thorac Surg 2011; 92: 1657-1662.

24. Kohler C, Attigah N, Demirel S, et al. A technique for a selfmade bifurcated graft with bovine pericardial patch in infectious vascular reconstruction. Journal of Vascular Surgery Cases and Innovative Techniques 2016; 2(4): 158-160.

25. Kunitomo R, Hara M, Utoh J, et al. Patch reconstruction of the mitral annulus for active infective endocarditis with annular abscess. Ann Thorac Cardiovasc Surg. 2001 Feb; 7(1): 52-55.

26. O'Connor S, Andrew P, Batt M, Becquemin JP. A systematic review and meta-analysis of treatments for aortic graft infection. J Vasc Surg 2006; 44: 38-45.

27. Ryan SV, Calligaro KD, Scharff J, Dougherty MJ. Management of infected prosthetic dialysis arteriovenous grafts. J Vasc Surg 2004; 39: 73-78.

28. Revest M, Camou F, Senneville E, et al. Medical treatment of prosthetic vascular graft infections: review of the literature and proposals of a Working Group. Int J Antimicrob Agents 2015; 46: 254-265.

29. Kouchoukos NT, Marschall WG, Wedige-Stecker TA. Eleven year experience with composite graft replacement of the ascending aorta and aortic valve. J Thorac Cardiovasc Surg 1986; 92: 691-705.

30. Svenson L, Crawford ES, Hess KR, et al. Composite valve graft replacement of the proximal aorta: comparison of techniques in 348 patients. Ann Thorac Surg 1992; 54: 427-439.

31. Kouchoukos NT. Inclusion (aneurysm wrap) technique for composite graft replacement of the ascending aorta and aortic valve. J Thorac Cardiovasc Surg 1988; 96: 967.

32. Cabrol C, Pavie A, Gandjabakhch I, et al. Complete replacement of the ascending aorta with reimplantation of the coronary arteries: new surgical approach. J Thorac Cardiovasc Surg 1981; 81: 309-315.
33. Coselli JS, Crawford ES. Composite valve-graft replacement of aortic root using separate Dacron tube for coronary artery reattachment. Ann Thorac Surg. 1989; 47(4): 558-565.

34. Yakut C. A new modified Bentall procedure: the flanged technique. Ann Thorac Surg. 2001; 71(6): 2050-2052.

35. Fattori R, Descovich B, Bertaccini P, et al. Composite graft replacement of the ascending aorta: leakage detection with gadolinium-enhanced MR imaging. Radiology 1999; 212: 573577.

36. Mesana TG, Caus T, Gaubert JY, et al. Late complications after prosthetic replacement of the ascending aorta: what did we learn from routine magnetic resonance imaging followup? Eur J Cardiothorac Surg 2000; 313-320.

37. Dossche KM, Schepens MAAM, Morshuis WJ, et al. A 23 year experience with composite valve graft replacement of the aortic root. Ann Thorac Surg 1999; 67: 1070-1077.

38. Grapow MT, Matt P, Zerkowski HR, Bernet F. Pseudoaneurysm in a Marfan patient 16 years after Bentall operation. Asian Cardiovasc Thorac Ann 2004; 12: 182-183.

39. Milano VD, Pratali S, Mecozzi G, et al. Fate of coronary ostial anastomoses after the modified Bentall procedure. Ann Thorac Surg 2003; 75: 1797-1802.

40. Okamoto K, Casselman FP, De Geest R, Vanermen H. Giant left coronary ostial aneurysm after modified Bentall procedure in a Marfan patient. Interact Cardiovasc Thorac Surg 2008; 7: 1164-1166.

41. Meijboom LJ, Nollen GJ, Merchant N, et al. Frequency of coronary ostial aneurysms after aortic root surgery in patients with the Marfan syndrome. Am J Cardiol 2002; 89: 1135-1138.

42. Chowdhury UK, Rao K, Narang R, et al. An alternative technique of coronary button implantation in patients undergoing modified Bentall's procedure. J Card Crit Care 2017; 1(1): 51-54.

43. Chowdhury UK, George N, Sankhyan LK, et al Intermittent antegrade and continuous retrograde coronary sinus cold blood cardioplegia to prevent and reverse ischemic and reperfusion damage in patients undergoing Bentall's procedure: A clinical report on 130 patients. International Journal of Clinical Case Studies and Reports 2019; 1(2): 23-32.

44. Chowdhury UK, George N, Singh S, et al. Fate of the coronary ostial and distal aortic anastomoses after modified Bentall's operation (UKC's Modification). J Surg \& Surgical Tech 2020; 2(1): 11-20.

45. Chowdhury UK, George N, Gudala V, et al. Bentall's procedure for annuloaortic ectasia and severe aortic regurgitation in a patient with repaired tetralogy of Fallot and aortic valvular reconstruction. World Journal of Pediatric and Congenital Heart Surgery, 2019; 10(5): 648-650.

46. Saporito WF, Pires AC, Cardoso SH, et al. Bovine pericardium retail preserved in glutaraldehyde and used as a vascular patch. BMC Surg 2011; 11: 37.

47. Quinones MA, Pickering E, Alexander JK. Percentage of shortening of the echocardiographic left ventricular dimension. Its use in determining ejection fraction and stroke volume. Chest 1978; 74: 59-65.

48. Chowdhury UK, Patel K, Kumari L, et al. Tissue Doppler imaging-derived mitral and tricuspid annular velocities: Nonpredictors of operative outcome in patients undergoing pericardiectomy for chronic constrictive pericarditis. Journal of Cardiology and Diagnostics Research 2019; 2(2): 67-83.

49. Chowdhury UK, George N, Singh S, et al. Total pericardiectomy via modified left anterolateral thoracotomy without cardiopulmonary bypass. A video presentation. Annals 
of Thoracic Surgery, 2021; doi: https: //doi.org/10.1016/j.athoracsur.2020.10.045

50. Sankhyan LK, Chowdhury UK, Bansal N, Hasija S. Intra-aortic balloon counterpulsation following Bentall's procedure for annuloaortic ectasia. Ann Short Reports 2018; 1: 1023.

51. Sankhyan LK, Chowdhury UK, George N, et al. Iatrogenic injuries during retrograde delivery of cardioplegia- Prevention, diagnosis and management: A collective review. J Cardiol 2019; 3(1): 000142.

52. Gabbay S, Guindy AM, Andrews JF, Amato JJ, Seaver P, Khan MY. New outlook on pericardial substitution after open heart operations. Ann Thorac Surg. 1989; 48: 803-811.

53. Kajihara N, Eto M, Oishi Y, Boku N, Kuwahara K, Nishiguchi $\mathrm{N}$, et al. Three-layered synthetic pericardial substitutes reduce postoperative pericardial adhesions. J Thorac Cardiovasc Surg. 2005; 129: 18-24.

54. Malm T, Bowald S, Bylock A, Busch C. Prevention of postoperative pericardial adhesions by closure of the pericardium with absorbable polymer patches. An experimental study. J Thorac Cardiovasc Surg. 1992; 104: 600-606.

55. Meus PJ, Wernly JA, Campbell CD, Takanashi Y, Pick RL, Zhao-Kun Q, et al. Long-term evaluation of pericardial substitutes. J Thorac Cardiovasc Surg. 1983; 85: 54-61.

56. Obermiller JF, Hodde JP, McAlexander CS, et al. A comparison of suture retention strengths of three biomaterials. Med Sci Monit. 2004; 10(1): PI1-PI5.

57. Chang Y, Tsai CC, Liang HC, Sung HW. In vivo evaluation of cellular and acellular bovine pericardia fixed with a naturally occurring crosslinking agent (genipin). Biomaterials 2002; 23: 2447-2457.

58. Bhat DJ, Tellis VA, Kohlberg WI, et al. Management of sepsis involving expanded polytetrafluoroethylene grafts for hemodialysis access. Surgery 1980; 87: 445-450.

59. Kim GF, Kwon TW, Cho YP, et al. Carotid endarterectomy with bovine patch angioplasty: a preliminary report. Cardiovascular Surgery. 2001; 9(5): 458-462.

60. Cunanan CM, Cubbling CM, Dinh TT, et al. Tissue characterization and calcification potential of commercial bioprosthetic heart valve. Ann Thorac Surg. 2001; 715 Suppl: S417-S421.

61. Marien BJ, Raffetto JD, Seidman CS, et al. Bovine pericardium vs. Dacron for patch angioplasty after carotid endarectomy. Arch Surg 2002; 137: 785-788.

62. Grimsley BR, Wells JK, Pearl GJ, et al. Bovine pericardial patch angioplasty in carotid endarterectomy. Am Surg 2001; 67: 890-895.

63. Biasi GM, Sternjakob S, Mingazzini PM, Ferrari SA. Nine-year experience of bovine pericardium patch angioplasty during carotid endarterectomy. J Vasc Surg 2002; 36: 271-277.

64. Zeltsman D, Tzarnas CD, Kerstein MD. Management of vascular prosthetic infections: results of long-term follow-up. Am Surg 1999; 65: 331-333.

65. Calligaro KD, Veith FJ, Gupta SK, et al. A modified method for management of prosthetic graft infections involving an anastomosis to the common femoral artery. J Vasc Surg 1990; 11: 485-492.

66. Chang Y, Lai PH, Wei HJ, et al. Tissue regeneration observed in a basic fibroblast growth factorloaded porous acellular bovine pericardium populated with mesenchymal stem cells. J Thorac Cardiovasc Surg. 2007; 134(1): 65-73.

67. Chang Y, Lai PH, Wang CC, et al. Mesothelium regeneration on acellular bovine pericardia loaded with an angiogenic agent (ginsenoside Rg1) successfully reduces postsurgical pericardial adhesions. J Thorac Cardiovasc Surg. 2006; 132(4): 867-874.
68. Imparato AM. The role of patch angioplasty after carotid endarterectomy. J Vasc Surg. 1988; 7(5): 715-716.

69. Rerkasem K, Rothwell PM. Patch angioplasty versus primary closure for carotid endarterectomy. Cochrane Database Syst Rev. 2009; 7.4 CD000160.

70. Neuhauser B, Oldenburg WA. Polyester vs. bovine pericardial patching during carotid endarterectomy: early neurologic events and incidence of restenosis. Cardiovasc Surg. 2003; 11(6): 465-470.

71. Muto A, Nishibe T, Dardik H, Dardik A. Patches for carotid artery endarterectomy: current materials and prospects. J Vasc Surg 2009; 50: 206-213.

72. Byrne J, Feustel P, Darling III RC. Primary closure, routine patching, and eversion endarterectomy: what is the current state of the literature supporting use of these techniques? Semin Vasc Surg. 2007; 20(4): 226-235.

73. Calligaro KD, Veith FJ, Schwartz ML, et al. Are gram-negative bacteria a contraindication to selective preservation of infected prosthetic arterial grafts? J Vasc Surg 1992; 16: 337-346.

74. Matsagas MI, Bali C, Arnaoutoglou E, et al. Carotid endarterectomy with bovine pericardium patch angioplasty: mid-term results. Ann Vasc Surg. 2006; 20(5): 614-619.

75. Krishnan S, Clowes AW. Daron patch infection after carotid endarterectomy: case report and review of literature. Ann Vasc Surg. 2006; 6: 672-677.

76. Derksen WJ, Verhoeven BA, van de Mortel RH, et al. Risk factors for surgical-site infection following common femoral artery endarterectomy. Vascular and Endovasc Surg. 2009; 43(1): 69-75.

77. Smith VC, Knauf DG, Alexander JA, et al. Bovine pericardial patch fibrosis requiring reoperation. J of Inves Surg. 1988; 1(4): 289-290.

78. Kacowak MH, Levett JM, Majoney DL, et al. Comparative studies of prosthetic materials in the left atrium of the dog. Virchows Arch[A]. 1987; 411(2): 173-177.

79. Bellini A, Mattoli S. The role of fibrocyte, a bone marrow derived mesenchymal progenitor, in reactive and reparative fibroses. Labor Invest. 2007; 87(9): 858-870.

80. Schoen FJ, Levy RJ. Calcification of tissue heart valve substitutes: progress toward understanding and prevention. Ann Thorac Surg 2005; 79: 1072-1080.

81. Schoen FJ. Are immune mechanisms important in tissue heart valve failure? A debate. J Heart Valve Dis 2001; 10: 458-459.

82. Schoen FJ, Levy RJ, Nelson AC. Onset and progression of experimental bioprosthetic heart valve calcification. Lab Invest 1985; 52(5): 523-532.

83. Schoen FJ, Harasaki H, Kim KM, et al. Biomaterial associated calcification: Pathology, mechanisms, and strategies for prevention. J Biomed Mater Re: Appl Boimater 1988; 22(A1): 11-36.

84. Konakci KZ, Bohle B, Blumer R, et al. Alpha-GAL on bioprostheses: xenograft immune response in cardiac surgery. Eur J Clin Invest 2005; 35: 17-23.

85. Manji RA, Zhu LF, Nijjar NK, et al. Glutaraldehyde-fixed bioprosthetic heart valve conduits calcify and fail from xenograft rejection. Circulation 2006; 114: 318-327.

86. Grimm M, Grabenwoger M, Eybl E, et al. Improved biocompatibility of bioprosthetic heart valves by L-glutamic acid treatment. J Card Surg 1992; 7: 58-64.

87. Lee C, Kim SH, Choi SH, Kim YJ. High-concentration glutaraldehyde fixation of bovine pericardium in organic solvent and postfixation glycine treatment: in vitro material assessment and in vivo anticalcification effect. Eur J Cardiothorac Surg 2011; 39: 381-387. 
88. Bailey MT, Pillarisetti S, Xiao H, Vyavahare NR. Role of elastin in pathologic calcification of xenograft heart valves. J Biomed Mater Res 2003; 66: 93-102.

89. Lim HG, Kim SH, Choi SY, Kim YJ. Anticalcification effects of decellularization, solvent, and detoxification treatment for genipin and glutaraldehyde fixation of bovine pericardium. Eur J Cardiothorac Surg 2012; 41: 383-390.

90. Samouillan V, Dandurand J, Lacabanne C, et al. Comparison of chemical treatments on the chain dynamics and thermal stability of bovine pericardium collagen. J Biomed Mater Res 2003; 64A: 330-338.

91. Pettenazzo E, Valente M, Thiene G. Octanediol treatment of glutaraldehyde fixed bovine pericardium: evidence of anticalcification efficacy in the subcutaneous rat model. Eur J Cardiothorac Surg 2008; 34: 418-422.

92. Vyavahare N, Hirsch D, Lerner E, et al. Prevention of bioprosthetic heart valve calcification by ethanol preincubation. Efficacy and mechanisms. Circulation 1997; 95: 479-488.

93. Vyavahare NR, Jones PL, Hirsch D, et al. Prevention of glutaraldehyde-fixed bioprosthetic heart valve calcification by alcohol pretreatment: further mechanistic studies. J Heart Valve Dis 2000; 9: 561-566.

94. Jorge-Herrero E, Fernández P, Escudero C, et al. Calcification of pericardial tissue pretreated with different amino acids. Biomaterials 1996; 17: 571-575.

95. Jorge-Herrero E, Turnay J, Calero P, et al. Calcification and identification of metalloproteinases in bovine pericardium after subcutaneous implantation in rats. J Mater Sci Mater Med. 2001; 12(10-12): 1013-1017.

96. Zhou J, Jiang H, Wang D, Hu S. A novel anti-calcification strategy of bovine pericardium using sodium bisulfite modification. J Heart Valve Dis 2009; 18: 180-186.

97. Gratzer PF, Pereira CA, Lee JM. Solvent environment modulates effects of glutaraldehyde crosslinking on tissuederived biomaterials. J Biomed Mater Res 1996; 31: 533-543.

98. Pathak CP, Adams AK, Simpson T, et al. Treatment of bioprosthetic heart valve tissue with long chain alcohol solution to lower calcification potential. J Biomed Mater Res 2004; 69A: 140-144.

99. Schoen FJ, Tsao JW, Levy RJ: Calcification of bovine pericardium used in cardiac valve bioprostheses. Am J Pathol 1986; 123(1): 134-145.

100. Schoen FJ. Are immune mechanisms important in tissue heart valve failure? A debate. J Heart Valve Dis 2001; 10: 458-459.

101. Courtman DW, Pereira CA, Kashef V, et al. Development of a pericardial acellular matrix biomaterial: biochemical and mechanical effects of cell extraction. J Biomed Mater Res 1994; 28: 655-666.

102. Park SS, Kim WH, Choi SY, Kim YJ. Removal of alpha-Gal epitopes from porcine aortic valve and pericardium using recombinant human alpha galactosidase A. J Korean Med Sci 2009; 24: 1126-1131.

103. Macher BA, Galili U. The Galalpha1,3Galbeta1,4GlcNAc-R (alpha-Gal) epitope: a carbohydrate of unique evolution and clinical relevance. Biochim Biophys Acta 2008; 1780: 75-88.
104. Wilson GJ, Courtman DW, Klement P, et al. Acellular matrix: a biomaterials approach for coronary artery and heart valve replacement. Ann Thorac Surg 1995; 60: S353-S358.

105. Chang Y, Tsai CC, Liang HC, Sung HW. Reconstruction of the right ventricular outflow tract with a bovine jugular vein graft fixed with a naturally occurring crosslinking agent (genipin) in a canine model. J Thorac Cardiovasc Surg. 2001; 122: 12081218.

106. Sung HW, Chen CN, Huang RN, Hsu JC, Chang WH. In vitro surface characterization of a biological patch fixed with a naturally occurring crosslinking agent. Biomaterials. 2000; 21: 1353-1362.

107. Sung HW, Huang RN, Huang LLH, Tsai CC. In vitro evaluation of cytotoxicity of a naturally occurring cross-linking reagent for biological tissue fixation. J Biomater Sci Polym Ed. 1999; 10: 63-71.

108. Bonduki CE, Lourenço DM, Motta EL, et al. Effect of estrogenprogestin hormonal replacement therapy on blood coagulation and fibrinolysis in postmenopausal women. Clinics 2007; 62(5): 553-560.

109. Hruska KA. Vascular smooth muscle cells in the pathogenesis of vascular calcification. Circ Res. 2009; 104(6): 710-711.

110. Wada T, McKee MD, Steitz S, et al. Calcification of vascular smooth muscle cell cultures: inhibition by osteopontin. Cir Res. 1999; 84(2): 166-178.

111. Tintut Y, Alfonso Z, Saini T, et al. Multilineage potential of cells from the artery wall. Circulation. 2003; 108(20): 25052510 .

112. Doherty MJ, Ashton BA, Walsh S, et al. Vascular pericytes express osteogenic potential in vitro and in vivo. J Bone Miner Res. 1998; 13(5): 828-838.

113. Jono S, Peinado C, Giachelli CM, et al. Phosphorylation osteopontin is required for inhibition of vascular smooth muscle cell calcification. J Biol Chem. 2000; 275(26): 20197-20203.

114. Mathew S, Tustison KS, Sugatani T, et al. The mechanism of phosphorus as a cardiovascular risk factor in chronic kidney disease. J Am Soc Nephrol. 2008; 19(6): 1092-1105.

115. Chen $\mathrm{CH}$, Wei HJ, Lin WW, et al. Porous tissue grafts sandwiched with multilayered mesenchymal stromal cell sheets induce tissue regeneration for cardiac repair. Cardiovasc Res. 2008; 1: 80(1): 88-95.

116. Griffith LG, Naughton G. Tissue engineering: current challenges and expanding opportunities. Science. 2002; 295: 1009-1015.

117. Shea LD, Smiley E, Bonadio J. DNA delivery from polymer matrices for tissue engineering. Nat Biotechnol. 1999; 17: 551557.

118. Liang HC, Chen CT, Chang Y, Huang YC, Chen SC, Sung HW. A novel angiogenic agent (ginsenoside Rg1) loaded in an acellular biological tissue for tissue regeneration. Tissue Eng. 2005; 11: 835-846.

119. Whitaker D, Papadimitriou JM, Walters M. The mesothelium: its fibrinolytic properties. J Pathol. 1982; 136: 291-300.

120. Elmadbouh I, Chen Y, Louedec L, Silberman S, Pouzet B, Meilhac O, et al. Mesothelial cell transplantation in the infarct scar induces neovascularization and improves heart function. Cardiovasc Res. 2005; 68: 307-317. 